\title{
NORMAS DE PUBLICACIÓN
}

La revista Espacio, Tiempo y Forma está dividida en siete series, Serie I: Prehistoria y Arqueología; Serie II: Historia Antigua; Serie III: Historia Medieval; Serie Iv: Historia Moderna; Serie v: Historia Contemporánea; Serie vı: Geografía; Serie vil: Historia del Arte. La periodicidad de la revista es anual.

En el año 2008 se inició una NUEva ÉPOCA con la renumeración de la revista. Desde el año 20I3 Espacio, Tiempo y Forma se publica como revista electrónica además de impresa. Este nuevo formato se ha integrado en el sistema electrónico Open Jornal System (OJs) y pretende agilizar los procesos editoriales y de gestión científica de la revista, garantizando el cumplimiento de los más altos estándares de calidad de las revistas científicas. Desde la plataforma ojs se facilita el acceso sin restricciones a todo su contenido desde el momento de la publicación.

Espacio, Tiempo y Forma, Serie I (ETF) publica trabajos inÉditos DE INVESTIGACIÓN Y DEBATES SOBRE PREHISTORIA Y ARQUEOLOGÍA, en especial artículos que constituyan una aportación novedosa, que enriquezcan el campo de investigación que abordan, o que ofrezcan una perspectiva de análisis crítico, tanto de ámbito nacional como internacional, y en lengua española o extranjera (preferiblemente en inglés o francés). ETF SERIE I sólo admite TRABAJOS ORIGINALES E INÉDITOS que no hayan sido publicados, ni vayan a serlo, en otra publicación, independientemente de la lengua en la que ésta se edite, tanto de manera parcial como total. Los trabajos recibidos en la revista son sometidos a evaluación externa.

ETF SERIE I cuenta por tres secciones: DOSSIER monográfico, ARTÍcUlos de temática variada y RECENSIONES. Los trabajos presentados a las dos primeras secciones tendrán, como máximo, una extensión de 90.000 caracteres con espacios (aprox. 40 páginas), incluidas las figuras, tablas y bibliografía. Los trabajos presentados a la sección de Recensiones deberán tener una extensión máxima de 9.600 caracteres (aprox. 4 páginas).

La publicación de un texto en Espacio, Tiempo y Forma no es susceptible de remuneración alguna. Esta revista provee acceso libre inmediato a su contenido en ojs bajo el principio de que hacer disponible gratuitamente la investigación fomenta un mayor intercambio de conocimiento global. Los autores conservan los derechos de autor y garantizan a la revista el derecho de ser la primera publicación del trabajo al igual que licenciarlo bajo una Creative Commons Attribution License que permite a otros compartir el trabajo con un reconocimiento de la autoría del trabajo y la publicación inicial en esta revista. Se anima a los autores a establecer acuerdos adicionales para la distribución no exclusiva de la versión de la obra publicada en la revista (por ejemplo, situarlo en un repositorio institucional o publicarlo en un libro), con un reconocimiento de su publicación inicial en esta revista. Se permite y se anima a los autores a difundir sus trabajos electrónicamente ya que puede dar lugar a intercambios productivos, así como a una citación más temprana y mayor de los trabajos publicados. 


\section{ENVÍO DE ORIGINALES}

Desde el año 2013 todo el proceso editorial se realiza a través de la plataforma ojs, donde encontrará normas actualizadas:

\section{http://e-spacio.uned.es/revistasuned/index.php/ETFI/index}

Es necesario registrarse en primer lugar, y a continuación entrar en IDENTIFICACIÓN (en la sección «Envíos on line») para poder enviar artículos, comprobar el estado de los envíos o añadir archivos con posterioridad.

El proceso de envío de artículos consta de cinco pasos (lea primero con detenimiento toda esta sección de manera íntegra antes de proceder al envío).

I. En el PASO I hay que seleccionar la sección de la revista (ETF I cuenta con tres secciones: Dossier monográfico, artículos de temática variada y recensiones) a la que se remite el artículo; el idioma; cotejar la lista de comprobación de envío; aceptar el sistema de copyright; si se desea, hacer llegar al Editor/a de la revista comentarios y observaciones (en este último apartado se pueden sugerir uno o varios posibles evaluadores, siempre que por su capacidad científica sean considerados expertos en la cuestión tratada en el artículo, lo que en ningún caso implica la obligación de su elección como revisores por parte de Consejo de Redacción de la revista).

2. En el PASO 2 se subirá el fichero con el artículo siguiendo escrupulosamente las indicaciones que se indican en este apartado:

* Archivo en formato compatible con MS WORD (que denominamos «original»), sin ninguna referencia a la identidad del autor o autores dentro del texto, eliminando cualquier elemento que aporte información que sugiera la autoría, como proyecto en el que se engloba o adscribe el trabajo. Para eliminar el nombre/s del autor/es en el texto, se utilizará la expresión «Autor» y año en las referencias bibliográficas y en las notas al pie de página, en vez del nombre del autor, el título del artículo, etc. Este es el archivo que se enviará a los revisores ciegos para su evaluación, y por ello se recuerda a los autores la obligatoriedad de seguir para este archivo las normas para asegurar una revisión ciega hecha por expertos. Tampoco han de incorporarse imágenes, gráficos ni tablas en este archivo (se incorporan en el Paso 4 de manera independiente), aunque sí se debe dejar las llamadas en el texto a dichos elementos allá donde procedan. El archivo ha de ser llamado con su propio nombre: NOMBRE_DEL_ARTÍCULO.DOC. Las normas de edición del texto se encuentran más abajo, léalas con atención.

3. En el paso 3 se rellenarán todos los campos que se indican con los datos del autor o autores (es imprescindible que se rellenen los datos obligatorios de todos los autores que firman el artículo). Igualmente hay que introducir en este momento los datos correspondientes a los campos Título y Resumen, sólo en el idioma original del 
artículo, así como los principales metadatos del trabajo siguiendo los campos que se facilitan (recuerde que una buena indexación en una revista electrónica como ETF SERIE I facilitará la mejor difusión y localización del artículo); y, si los hubiere, las agencias o entidades que hayan podido financiar la investigación que a dado pie a esta publicación.

4. En el PASO 4 se pueden subir todos los archivos complementarios: de manera obligatoria se remitirá un archivo con los datos del autor, y de manera opcional se subirán si los hubiere, individualmente, tanto los archivos con las imágenes, gráficos o tablas que incluya el artículo, como un archivo con la información correspondiente a las leyendas o pies de imágenes, gráficos y tablas. Hay que tener en cuenta las siguientes indicaciones:

* Archivo en formato compatible con MS wORD con los datos completos del autor y autores: nombre y apellidos, institución a la que pertenece/n, dirección de correo electrónico y postal, y número de teléfono para contacto del autor principal. En este archivo sí se puede incluir la referencia al proyecto en el que se inscriba el trabajo ( $1+\mathrm{D}$, proyecto europeo, entidad promotora $\mathrm{o}$ financiadora, etc.).

* Archivos independientes con las imágenes y tablas del artículo. Las imágenes se enviarán en formato digital (.JPEG, .PNG O .TIFF) con una resolución mínima de 300 ppp. a tamaño real de impresión. Las ilustraciones (láminas, dibujos o fotografías) se consignarán como «FIGURA» (p. ej., FIGURA I, FIGURA 2...). Por su parte, los cuadros y tablas se designarán como «TABLA». Las Figuras y Tablas se enviarán en archivos individualizados indicando el número de figura/tabla, siempre en formato escalable (.DOC, .DOCX, .RTF, .AI, .EPS, etc.).

* Archivo en formato compatible con ms wORD con las leyendas o pies de imágenes y tablas (recuerde que en el archivo MS WORD que llamamos «original» ha de colocar donde proceda la llamada a la Figura o Tabla correspondiente entre paréntesis). El/los autor/es está/n obligado/s a citar la fuente de procedencia de toda documentación gráfica, cualquiera que sea su tipo. La revista declina toda responsabilidad que pudiera derivarse de la infracción de los derechos de propiedad intelectual o comercial.

Durante el Paso 4, al insertar cada archivo complementario se le da posibilidad de que los evaluadores puedan ver dichos archivos. Sólo debe dar a esta opción en los archivos de figuras y tablas, y en el de los pies de foto, siempre y en todos los casos si con ello no se compromete la evaluación ciega. Nunca pulse esta opción en el caso del archivo con los datos el autor/es.

En este momento puede subir también cualquier otro tipo de archivo que crea necesario para la posible publicación del artículo. 
5. El último, paso, el paso 5, le pedirá que CONFiRme o CANCELE el envío. Si por cualquier cuestión, decide cancelar su envío, los datos y archivos quedarán registrados a la espera de que confirme el envío o subsane algún tipo de error que haya detectado (una vez se haya vuelto a registrar pulse sobre el envío Activo y luego sobre el nombre del artículo para poder completar el proceso). Igualmente tiene la opción posterior de borrar todo el envío y anular todo el proceso.

\section{MODIFICACIÓN DE ARCHIVOS CON POSTERIORIDAD AL ENVIIO DEL ORIGINAL, ENVÍO DE REVISIONES SOLICITADAS EN EL PROCESO DE REVISIÓN Y ENVIIO DEL ARTÍCULO ACEPTADO}

Existen diversas circunstancias, como errores del autor/es o las solicitudes de modificaciones o mejoras durante el proceso de revisión, que podrán generar uno o más nuevos envíos por parte del autor/es a esta plataforma.

Para todos los casos el autor principal que haya realizado el envío debe seguir los siguientes pasos:

I. ENTRAR CON SUS CLAVES DE REGISTRO (recuerde anotarlas en lugar seguro la primera que vez que se registra, aunque es posible solicitar al sistema la generación de nuevas claves).

2. PUlSAR SObRE EL ENVÍO QUE LE APARECE COMO ACTIVO.

3. Le aparecerá una pantalla con el nombre y estado de su artículo, si PULSA SOBRE EL TíTULO DE SU TRABAJO llegará a la pantalla con los datos completos de su envío. En esta pantalla encontrará en la parte superior las pestañas RESUMEN, REVISIÓN Y EDITAR.

3.I. Si lo que quiere es añadir algún archivo complementario porque haya sido mal recibido, porque haya sido olvidado o por subsanar cualquier error advertido por parte del Editor/a o del propio autor/a, entre en la pestaña RESUMEN y pulse sobre la posibilidad de añadir fichero adicional. Igualmente puede en este momento modificar o complementar los metadatos del artículo.

3.2. Si el envío ha sido aceptado en primera estancia por el Consejo de Redacción, y dentro del proceso de revisión por pares ciegos se le notifica alguna sugerencia de mejora o modificación, entonces deberá entrar en la pestaña REVISIÓN, donde encontrará detallado todo el proceso y estado de la revisión de su artículo por parte del Editor/a y de los Revisores/as, allí podrá subir una nueva versión del autor/a en la pestaña DECISIÓN EDITORIAL. Recuerde que aún debe mantener el anonimato de la autoría en el texto, por lo que los archivos con las correcciones y revisiones deben ser remitidos aún en formato .PDF. 
3.3. Una vez finalizado y completado el proceso de revisión por pares, si el artículo ha pasado satisfactoriamente todos los filtros se iniciará la corrección formal del trabajo de cara a su publicación tanto en la edición electrónica como en la edición en papel de la revista. Después de registrarse y pulsar sobre el título debe entrar en la pestaña EDITAR y seguir las instrucciones que le notifique el Editor/a. En este momento y de cara al envío del artículo para su maquetación y publicación, el archivo original que en su momento remitió en MS WORD para la revisión, siempre exento de imágenes, figuras o tablas, debe ser ahora enviado en formato de texto compatible con MS WORD.

\section{VERSIÓN PRE PRINT}

Además de lo anterior, existe la posibilidad de publicar una versión pre print de su trabajo en la revista electrónica con anterioridad a la versión definitiva maquetada. Para ello, en esta fase se le requerirá para que junto a la versión definitiva en formato compatible con MS WORD sólo con el texto que se remite a la imprenta (junto a los archivos con las imágenes, figuras y tablas si las hubiere, que ya había remitido el autor/es en el primer envío), ha de remitir una versión completa de su artículo en .PDF ya con el nombre/s del autor/es, así como con las imágenes o tablas incorporadas, junto a las leyendas precisas, incluidas al finalizar el texto, antes de la bibliografía. La puede subir registrándose e incluyéndola en los archivos complementarios del apartado RESUMEN. De esta forma el autor verá en la versión electrónica, con una importante antelación con respecto a la versión en papel, el artículo definitivo aprobado, y podrá citar como prepublicado su artículo (este archivo, lógicamente, es de carácter provisional, no va paginado, y es sustituido con posterioridad cuando se incorpora la versión definitiva).

Si el autor se demora o incumple los plazos en las fases de Revisión o Edición, el Consejo de Redacción de la revista puede decidir la no publicación del artículo o su postergación automática para un número posterior.

\section{NORMAS DE EDICIÓN}

Las siguientes normas de edición deben ser tenidas en cuenta para el archivo «original» editado en MS WORD (Paso 2):

\section{DATOS DE CABECERA}

* En la primera página del trabajo deberá indicarse el título del trabajo EN SU LENGUA ORIGINAL Y SU TRADUCCIÓN AL INGLÉS. Recuerde que no debe aparecer el nombre del autor, ni la institución a la que pertenece (debe remitirse en un fichero independiente en el paso 4: añadir ficheros complementarios). 
* Un resumen en castellano del trabajo, junto a su correspondiente VERSIÓN EN INGLÉS, no superior a I.OOo caracteres con espacios. En el resumen es conveniente que se citen los objetivos, metodología, resultados y conclusiones obtenidas.

* Se añadirán también unas palabras Clave, en ambos idiomas, separadas POR PUNTO Y COMA (;), que permitan la indexación del trabajo en las bases de datos científicas. Éstas no serán inferiores a cuatro ni excederán de ocho.

* En caso de que la lengua del texto original no sea el castellano, ni el inglés, el título, el resumen y las palabras claves se presentarán en el idioma original, junto con su versión en castellano e inglés.

* Las ilustraciones se enviarán en fichero independiente a este texto «original», igualmente se remitirá un archivo con la relación de ilustraciones y sus correspondientes leyendas (pies de imágenes).

\section{Presentación del texto}

* Se facilita en la plataforma una HOJA DE ESTILO que incluye las características que se detallan a continuación, y se recomienda al autor/es su uso para evitar demoras en los posteriores procesos de corrección y maquetación.

* El formato del documento debe ser compatible con ms word. El tamaño de página será DIN-A4. El texto estará paginado y tendrá una extensión máxima de 90.000 caracteres con espacios (40 páginas), incluidas las figuras, tablas y bibliografía.

* Las imáGenes y tABLAS, así como la relación numérica y la leyenda, tanto de las figuras como de las tablas, se adjuntarán en archivos aparte (en el paso 4). Se consignarán como FigURA I, FIGURA 2... Por su parte, los cuadros y tablas se designarán como TABLA I, TABLA $2 . .$. Las referencias a ilustraciones deben estar incluidas en el lugar que ocuparán en el texto. Su número queda a criterio del autor, pero se aconseja un máximo de 15 imágenes. En todos los casos debe citarse la procedencia de la imagen. Al comienzo del trabajo se podrá incluir una nota destinada a los agradecimientos y al reconocimiento de las instituciones o proyectos que financian el estudio presentado.

* Encabezados. Los encabezamientos de las distintas partes del artículo deberán ser diferenciados, empleando, si procede, una jerarquización de los apartados ajustada al modelo que se propone:

1. Título del capítulo

1.1. Título del epígrafe

1.1.1. Título del subepígrafe 
3. Estilo

* El texto se presentará sin ningún tipo de formato ni de sangría de los párrafos, y con interlineado sencillo.

* Se utilizarán únicamente tipos de letra con codificación unicode.

* Las citas literales, en cualquier lengua original, se insertarán en el cuerpo del texto en redonda, siempre entre comillas dobles. Si la cita supera las tres líneas se escribirá en texto sangrado, sin comillas.

* Se evitará, en lo posible, el uso de negrita.

* Las siglas y abreviaturas empleadas deben ser las comúnmente aceptadas dentro de la disciplina sobre la que verse el trabajo.

* Los términos en lengua original deberán escribirse en cursiva, sin comillas: in situ, on-line.

* El resto de normas editoriales se ajustarán a lo indicado en: Real Academia Española, Ortografía de la lengua española, Madrid, Espasa Calpe, 20 o.

\section{Bibliografía}

Las referencias se citarán en el texto indicando, entre paréntesis, el apellido del autor junto con el año de edición de la obra citada (Cabrera 2006). En caso de que al autor se le haga mención en la misma frase, sólo se indicará el año de la publicación ([...] según la hipótesis propuesta por Cabrera (2006) [...]). Los sufijos $(a, b, c . .$.$) se emplearán en el texto y en la relación bibliográfica$ final para diferenciar trabajos de un autor publicados en un mismo año. Se recomienda hacer mención a la página concreta de la cita (Cabrera 2006: I25). Si existen dos autores se consignarán ambos (González Echegaray \& Freeman I97I). En caso de ser más de dos autores se añadirá al primero et al. (Karlin et al. 1988). Los textos citados que se encuentren en prensa tendrán que tener todos los datos editoriales para ser admitidos. No se aceptan citas de obras inéditas (salvo tesis doctorales, memorias de DEA e informes administrativos).

Las referencias bibliográficas se recopilarán por orden alfabético al final del artículo:

* Libro de editor

HAGER, L.D. (ed.) 1997: Women in human evolution. Routledge. London.

Bonifay, E. \& Vandermeersch, B. (eds.) 1991: Les premiers européens. Actes du 114 Congrès National des Sociétés Savantes. Editions du CTHS. Paris.

* CApítulo de libro

CONKEY, M.W. 1997: «Mobilizing ideologies: palaeolithic 'art', gender trouble and thinking about alternatives». En L.D. Hager (ed.): Women in human evolution. Routledge. London: 172-207. 
* Libro de autor/autores

Noble, W. \& Davidson, I. 1996: Human evolution, language and mind. A psychological and archaeological inquiry. Cambridge University Press. Cambridge.

* Revista

Lerol-Gourhan, A. 1961: «Les fouilles d'Arcy-sur-Cure (Yonne)». Gallia Préhistoire IV: $3-16$.

\section{* Tesis doctoral o deA}

Bourguignon, L. 1997: Le Moustérien de type Quina: nouvelle définition d'une technique. Tesis Doctoral. Université de Paris X-Nanterre. 